\title{
Predictive Factors for Elevated Postoperative Carbohydrate Antigen 19-9 Levels in Patients With Resected Pancreatic Cancer
}

\author{
CHISATO TAKAGI, YUTARO KIKUCHI, HIROFUMI SHIRAKAWA, SOJUN HOSHIMOTO, \\ MORIAKI TOMIKAWA, IWAO OZAWA, SHOICHI HISHINUMA and YOSHIRO OGATA \\ Department of Hepato-Biliary-Pancreatic Surgery, Tochigi Cancer Center, Utsunomiya, Japan
}

\begin{abstract}
Aim: In this study, we investigated the clinical significance of postoperative serum carbohydrate antigen $(C A)$ 19-9 in patients with pancreatic ductal carcinoma (PDAC). Patients and Methods: A series of 116 patients with macroscopically curative PDAC resection was retrospectively evaluated. The cut-off level for elevated postoperative CA 19-9 was $37 \mathrm{U} / \mathrm{ml}$. Results: Patients with high postoperative CA199 levels had a significantly poorer prognosis than patients with normal postoperative CA19-9 levels, as revealed by the logrank test. Multivariate analysis identified $R 1$ resection and preoperative serum CA19-9 level $\geq 400 \mathrm{U} / \mathrm{ml}$ independently predicted elevated postoperative CA $19-9$ levels. $R 1$ resection and preoperative serum $C A 19-9 \geq 400 \mathrm{U} / \mathrm{ml}$ were significantly associated with the recurrence of peritoneal dissemination and hepatic metastasis, respectively, within one year of operation. Conclusion: Elevated postoperative serum CA 19-9 level was associated with a poor prognosis and reflected positive resection margins and high preoperative CA 19-9 levels, which indicated presence of occult distant metastasis in patients with PDAC.
\end{abstract}

Pancreatic ductal adenocarcinoma (PDAC) is highly lethal, and surgical resection is the only curative treatment available. The 5-year survival of patients with curative resection of PDAC has been estimated to be $20 \%$ (1). Adjuvant and neoadjuvant chemotherapies are offered in clinical practice aiming to improve survival (2-6). Accurate prediction of prognosis and effective stratification are important for planning postsurgical treatment and designing clinical trials. The prognostic value of carbohydrate antigen

Correspondence to: Chisato Takagi, Tochigi Cancer Center, 4-9-13, Yohnan, Utsunomiya, Tochigi 320-0834, Japan. Tel: +81 286585151, Fax: +81 286585669, e-mail: chtakagi@ tochigi-cc.jp

Key Words: CA-19-9 antigen, neoplasm, micrometastasis, pancreatectomy, pancreatic neoplasm, treatment outcome.
(CA) 19-9 has been evaluated in patients with PDAC following curative resection, and it reportedly reflects tumor burden $(7,8)$. High postoperative serum (Post)-CA 19-9 levels have been reported as a prognostic factor, and elevated Post-CA 19-9 levels were reported to be a more powerful prognostic factor than preoperative serum (Pre)-CA 19-9 (911) level. High Post-CA 19-9 levels have been considered to be associated with microscopically positive surgical margin or occult distant metastasis; however, their relationship has not been adequately and statistically confirmed yet (10-12). In the present study, we aimed to investigate the clinical significance of elevated Post-CA 19-9 levels by analyzing which factors are predictive of elevated Post-CA 19-9 levels.

\section{Patients and Methods}

Patient population and study design. This retrospective cohort study evaluated patient data collected at the Tochigi Cancer Center. The protocol for this research project has been approved by a suitably constituted Ethics Committee of the institution (Approval No. C-200) and it conforms to the provisions of the Declaration of Helsinki.

A series of 166 patients with surgical resection for PDAC between January 2008 and December 2016 were included in the analysis. Eleven patients with macroscopically positive resection margin or distant metastasis were excluded. Further, Pre-CA 19-9 was measured within 6 weeks of surgery. The lowest serum CA19-9 level within 3 months after surgery was adopted as the Post-CA 19-9 level. We did not refer CA 19-9 value after initiation of adjuvant chemotherapy. Twenty-one patients with Pre-CA 19-9 <5 U/ml were excluded because they were considered nonsecretors. CA 19-9 values were not included in the analysis if serum total bilirubin was $\geq 2.0 \mathrm{mg} / \mathrm{dl}$ at the time of assay. Eighteen patients were also excluded because their Preor Post-CA 19-9 levels were unavailable. Finally, the remaining 116 patients were enrolled in the study.

The patients were stratified based on their Post-CA 19-9 levels into groups below or above the $37 \mathrm{U} / \mathrm{ml}$ reference upper limit of normal. The normal Post-CA 19-9 group included patients with concentrations $\leq 37 \mathrm{U} / \mathrm{ml}$, whereas the elevated Post-CA 19-9 group included those with concentrations $>37 \mathrm{U} / \mathrm{ml}$. Additional patient variables included in the analysis were age, sex, resectable status, preoperative treatment, operative method, combined resection of the 
portal vein (PV) or celiac artery (CA), histological grade, pathological tumor and node stage, resection margin status, and perioperative chemotherapy administration. Pathological tumor and node stage were classified using the criteria described in the Union for International Cancer Control (UICC) eighth edition (12).

Statistical analysis. Continuous variables are expressed as medians and interquartile range (IQR). Comparisons of the values of patient variables in the normal and elevated Post-CA 19-9 groups were performed with the Mann-Whitney $U$-test and Fisher's exact test, as appropriate. Overall survival (OS) was defined as the time from the date of surgery to either death from any cause or the last follow-up. Patients alive at the last follow-up were censored. The survival of patients with normal and elevated Post-CA 19-9 levels was estimated by the Kaplan-Meier method and compared by log-rank test.

Univariate and multivariate logistic regression analysis were used to identify factors that were independent predictive factors of elevated Post-CA 19-9 level. Factors with $p$-values $<0.2$ following univariate analysis were included in the multivariate analysis. Because we assumed that Pre- and Post-CA 19-9 levels were related, receiver operating characteristics (ROC) curve analysis was used to define the optimal cut-off value of Pre-CA 19-9 that predicted elevated Post-CA 19-9 level. The optimal cut-off was the value with the maximum sensitivity and specificity. The association of recurrence within one year of operation with Post-CA 19-9 level and independent predictive factors of elevated Post-CA 19-9 level were identified by multivariate analysis. $p$-Values $<0.05$ were considered statistically significant. The statistical analysis was conducted with the R 3.4.4 statistical package (https://www.r-project.org).

\section{Results}

Patient characteristics. Fifty-eight of the 116 patients (50\%) were males and $58(50 \%)$ were females. Their median age was 69 (IQR 63-76) years, and the median Pre-CA 19-9 was 205 (IQR 49-1191) U/ml. Pancreaticoduodenectomy was performed in 54 patients $(47 \%)$, total pancreatectomy in 7 (6\%), and distal pancreatectomy in $55(47 \%)$. PV resection was performed in $39(34 \%)$ and celiac artery (CA) resection in $6(5 \%)$. The histological characteristics included 5 patients $(4 \%)$ with UICC grade $\mathrm{G} 1,96(83 \%)$ with grade $\mathrm{G} 2$, and 15 (13\%) with grade G3 tumors. Thirteen patients $(11 \%)$ were stage T1, $56(48 \%)$ were stage T2, $43(37 \%)$ were stage $\mathrm{T} 3$, and $4(3.4 \%)$ were stage T4. Twenty-nine (25\%) were stage N0, 45 (39\%) were stage N1, and $42(36 \%)$ were stage N2. Surgery achieved R0 resection in 102 patients $(88 \%)$ and $\mathrm{R} 1$ resection in $14(12 \%)$. The median Post-CA 19-9 level was 30 (IQR 10-202) U/ml, and 84 patients $(72 \%)$ received adjuvant chemotherapy. Of these patients, 61 (73\%) received S-1 monotherapy, $21(25 \%)$ received gemcitabine monotherapy, and 2 (2\%) received gemcitabine plus S-1 therapy. Further, 1-, 3-, and 5-year OS were $75.8 \%, 35.2 \%$, and $22.3 \%$, respectively; median survival was 23.1 (range 1.5-107) months.

Normal and elevated Post-CA 19-9 levels. As shown in Table I, 62 patients (53\%) had a normal Post-CA 19-9 level and 54 (47\%) had elevated Post-CA 19-9 level. Patients with elevated
Table I. Comparison between patients with normal and elevated serum Post-CA19-9.

\begin{tabular}{|c|c|c|c|}
\hline & \multicolumn{2}{|c|}{ Postoperative CA19-9 } & \multirow[b]{2}{*}{$p$-Value } \\
\hline & $\leq 37 \mathrm{U} / \mathrm{ml}$ & $>37 \mathrm{U} / \mathrm{ml}$ & \\
\hline Number of patients & 62 & 54 & \\
\hline Male gender & $33(54)$ & $25(46)$ & 0.57 \\
\hline Age, years & $66(61-72)$ & $72(65-77)$ & 0.010 \\
\hline \multicolumn{4}{|l|}{ Preoperative serum } \\
\hline CA19-9, U/ml & $73(26-298)$ & $658(191-3195)$ & $<0.001$ \\
\hline \multicolumn{4}{|l|}{ Resectability status } \\
\hline $\mathrm{R}$ & $42(68)$ & $31(57)$ & 0.34 \\
\hline $\mathrm{BR}$ & $20(32)$ & $23(43)$ & \\
\hline \multicolumn{4}{|l|}{ Operative method } \\
\hline PD & $25(40)$ & $29(54)$ & 0.22 \\
\hline $\mathrm{TP}$ & $3(5)$ & $4(7)$ & \\
\hline DP & $34(55)$ & $21(39)$ & \\
\hline \multicolumn{4}{|l|}{ Vascular resection } \\
\hline PV & $15(24)$ & $24(44)$ & 0.029 \\
\hline $\mathrm{CA}$ & $3(5)$ & $3(6)$ & 1.00 \\
\hline \multicolumn{4}{|l|}{ Histological grade } \\
\hline G1 & $4(7)$ & $1(2)$ & 0.42 \\
\hline $\mathrm{G} 2$ & $49(79)$ & $47(87)$ & \\
\hline G3 & $9(14)$ & $6(11)$ & \\
\hline \multicolumn{4}{|c|}{ Tumor stage (UICC 8th ed.) } \\
\hline $\mathrm{T} 1$ & $9(15)$ & $4(7)$ & 0.60 \\
\hline $\mathrm{T} 2$ & $30(48)$ & $26(48)$ & \\
\hline $\mathrm{T} 3$ & $21(34)$ & $22(41)$ & \\
\hline $\mathrm{T} 4$ & $2(3)$ & $2(4)$ & \\
\hline \multicolumn{4}{|c|}{ Node stage (UICC 8th ed.) } \\
\hline No & $22(36)$ & $7(13)$ & $<0.001$ \\
\hline N1 & $27(43)$ & $18(33)$ & \\
\hline $\mathrm{N} 2$ & $13(21)$ & $29(54)$ & \\
\hline \multicolumn{4}{|c|}{ Surgical margin status } \\
\hline R0 & $60(97)$ & $42(78)$ & $<0.001$ \\
\hline R1 & $2(3)$ & $12(22)$ & \\
\hline \multicolumn{4}{|l|}{ Postoperative serum } \\
\hline CA19-9, U/mL & $10(6-16)$ & $242(66-904)$ & $<0.001$ \\
\hline \multicolumn{4}{|c|}{ Adjuvant chemotherapy } \\
\hline S-1 & $35(57)$ & $26(48)$ & 0.90 \\
\hline GEM & $13(21)$ & $8(15)$ & \\
\hline S-1 + GEM & $1(1)$ & $1(2)$ & \\
\hline \multicolumn{4}{|c|}{ Preoperative treatment } \\
\hline GEM & 0 & $1(2)$ & 0.41 \\
\hline S-1 + GEM & $4(7)$ & $4(7)$ & \\
\hline GEM + nabPTX & 0 & $2(4)$ & \\
\hline FOLFIRINOX & $2(3)$ & 0 & \\
\hline $\mathrm{S}-1+\mathrm{RTx}$ & $1(2)$ & $2(4)$ & \\
\hline
\end{tabular}

CA 19-9: Carbohydrate antigen 19-9; PD: pancreaticoduodenectomy; TP: total pancreatectomy; DP: distal pancreatectomy; PV: portal vein; CA: celiac axis; UICC Union for International Cancer Control; GEM gemcitabine; nabPTX nanoparticle albumin-bound paclitaxel; FOLFIRINOX combination of bolus and infusional fluorouracil, leucovorin, irinotecan and oxaliplatin. Data are expressed as median (interquartile range) or $\mathrm{n}(\%)$.

Post-CA 19-9 levels were older $(p=0.01)$, and their Pre-CA $19-9$ levels were higher $(p<0.001)$ than that in patients with 


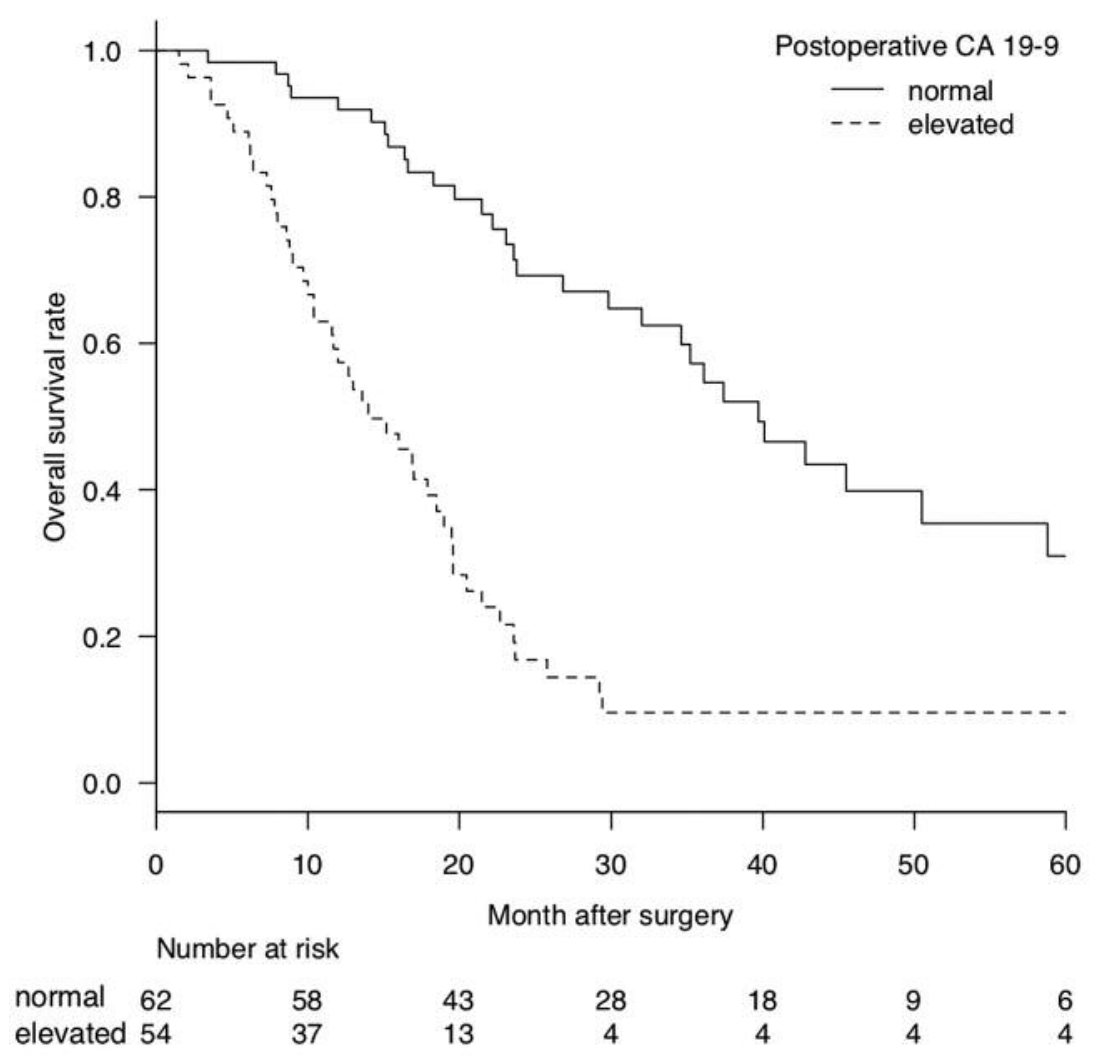

Figure 1. Overall survival of patients with normal and elevated serum Post-CA 19-9 levels.

normal Post-CA 19-9 levels. The PV resection $(p=0.029)$ and $\mathrm{R} 1$ resection $(p<0.001)$ rates were significantly higher in patients with elevated levels than in those with normal PostCA 19-9 levels. The tumor stage in the two groups was not significantly different, but the distribution of node stage was significantly different $(p<0.001)$. Median Post-CA 19-9 level was $10(\mathrm{IQR}=6-16) \mathrm{U} / \mathrm{ml}$ in patients with normal Post-CA 199 levels and 242 (IQR 66-904) U/ml in those with elevated Post-CA 19-9 levels $(p<0.001)$.

The Kaplan-Meier analysis of OS in patients with normal and elevated Post-CA 19-9 is shown in Figure 1. One- 3-, and 5-year OS and median survival time were significantly better in the normal $(92 \%, 57 \%, 31 \%$, and 39.7 months) than in the elevated $(57 \%, 10 \%, 10 \%$, and 14.0 months) Post-CA 19-9 group $(p<0.001)$.

Factors predictive of elevated Post-CA 19-9. The results of the univariate and multivariate logistic regression analysis of patient preoperative and pathological factors related to elevated postoperative serum CA19-9 levels are shown in Table II. The results of ROC curve analysis of Pre-CA 19-9 to predict elevated Post-CA 19-9 levels are shown in Figure 2. A Pre-CA 19-9 concentration of $396 \mathrm{U} / \mathrm{ml}$ was found to be the optimal cut-off value for prediction of an elevated Post-
CA 19-9 level. The sensitivity and specificity of $396 \mathrm{U} / \mathrm{ml}$ cut-off level were $67 \%$ and $79 \%$, respectively. The area under the ROC curve was 0.760 (95\% CI=0.671-0.849). For simplicity, $400 \mathrm{U} / \mathrm{ml}$ was adopted as the cut-off value. In univariate analysis, age $(p=0.022)$, Pre-CA19-9 $\geq 400 \mathrm{U} / \mathrm{ml}$ $(p<0.001)$, PV or CA resection $(p=0.014), \mathrm{N} 1-\mathrm{N} 2$ node stage $(p=0.007)$, and $\mathrm{R} 1$ resection $(p=0.009)$ were significantly associated with elevated Post-CA 19-9 levels. Multivariate analysis revealed that Pre-CA19-9 $\geq 400 \mathrm{U} / \mathrm{ml}$ (odds ratio [OR], 6.41; 95\% CI: 2.44-16.8; $p<0.001)$ and $\mathrm{R} 1$ resection (OR, 17.2; 95\% CI: 1.83-161, $p=0.01$ ) were independent predictive factors for elevated Post-CA 19-9 level.

Early PDAC recurrence. The nature of the first site recurrences within one year of operation that occurred in patients with high and low Post-CA 19-9, Pre-CA 19-19, and $\mathrm{R} 0$ or $\mathrm{R} 1$ resection are shown in Table III. Recurrence occurred in 66 of the 116 patients within one year of operation. Any observed metastasis $(p<0.001)$, hepatic metastasis $(p<0.001)$, and peritoneal dissemination $(p=0.020)$ were significantly more frequent in patients with elevated levels than with normal Post-CA 19-9 levels. Overall metastasis $(p<0.001)$, hepatic metastasis $(p<0.001)$, local recurrence $(p=0.049)$, and lymph node metastasis $(p=0.039)$ 


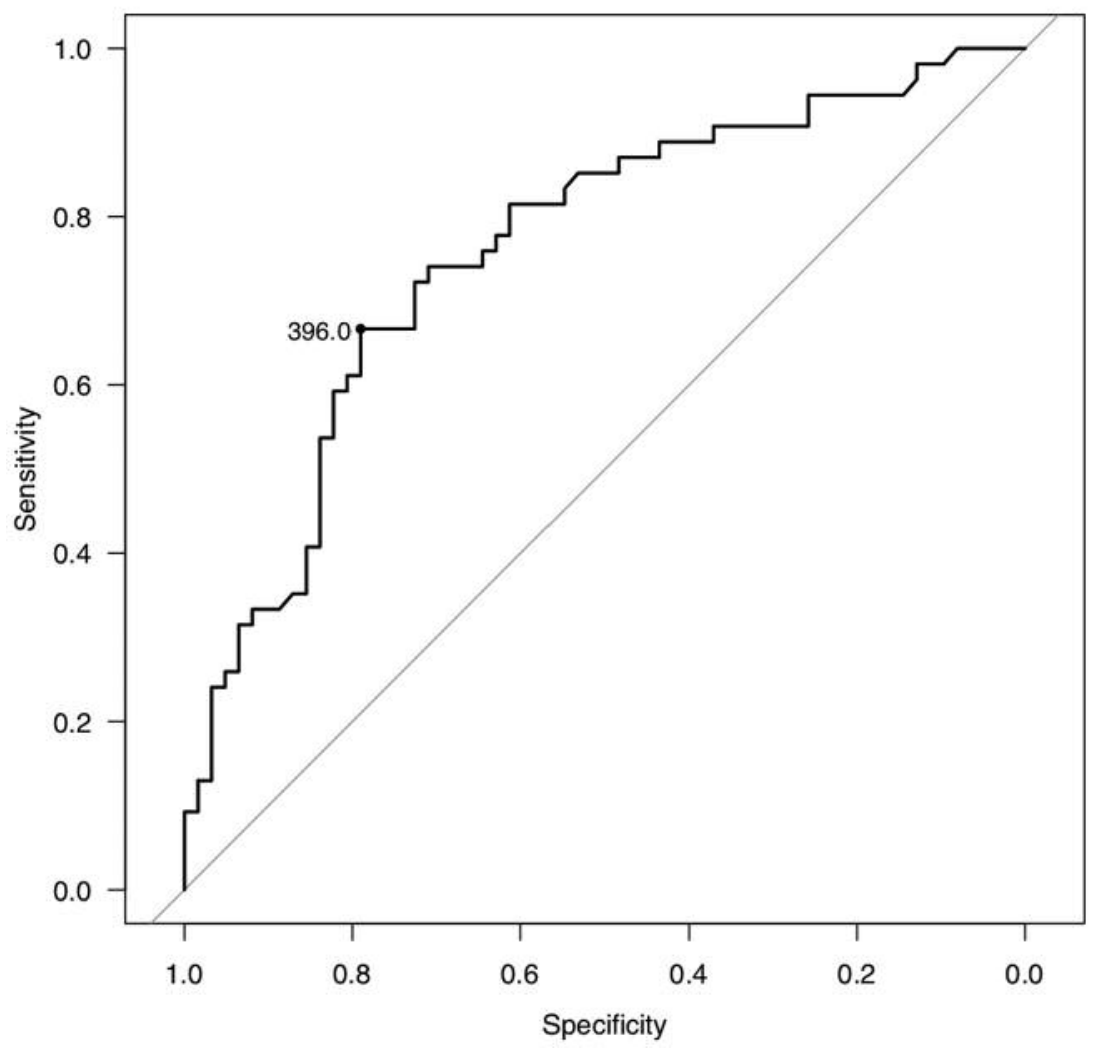

Figure 2. Receiver operating characteristic curve analysis of pre-CA 19-9 levels that predicted elevated Post-CA 19-9 levels.

were significantly higher in patients with a Pre-CA $19-9 \geq 400$ $\mathrm{U} / \mathrm{ml}$ than in those with Pre-CA 19-9 levels <400 U/ml. Overall metastasis $(p=0.023)$, peritoneal dissemination $(p=0.012)$ and local recurrence $(p=0.027)$ were more frequent in patients with $\mathrm{R} 1$ resection than in those with $\mathrm{R} 0$ resection.

\section{Discussion}

This retrospective cohort study investigated the factors predictive of elevated Post-CA 19-9 levels after curative resection for PDAC. Multivariate logistic regression showed that a Pre-CA 19-9 level $\geq 400 \mathrm{U} / \mathrm{ml}$ and $\mathrm{R} 1$ resection were independent prognostic factors for elevated Post-CA 19-9 levels. The patients with elevated Post-CA 19-9 levels were found to have higher rates of recurrence involving hepatic metastasis and peritoneal dissemination than that those with normal Post-CA 19-9 levels. R1 resection and a Pre-CA 199 level $\geq 400 \mathrm{U} / \mathrm{ml}$ were significantly associated with peritoneal dissemination and hepatic recurrence, respectively. The results are consistent with those of previous retrospective cohort studies reporting that high Post-CA 199 levels were associated with poor survival in patients with PDAC after resection $(9,10,13,14)$. However, the clinical factors associated with an increased risk of elevated CA 19-
9 levels were not described. In the present study, we identified the clinicopathological characteristics predictive of elevated Post-CA 19-9 levels.

The finding that elevated Post-CA 19-9 levels indicated the prognosis of PDAC patients after macroscopically curative resection is consistent with the findings of previous studies. Optimal Post-CA 19-9 predictive cut-off levels of $37,90,180$, and $200 \mathrm{U} / \mathrm{ml}$ have been reported $(7,9,10,13-$ 15). Two reports adopted the lowest p-value obtained by univariate analysis, which were 37 and $200 \mathrm{U} / \mathrm{ml}(7,11)$. Other studies used $70 \mathrm{U} / \mathrm{ml}$, a two-fold elevation of the upper limit of normal (15) or used 35 or $37 \mathrm{U} / \mathrm{ml}$ as cut-offs $(10,13,14)$. In the present study, a Post-CA 19-9 cut-off level of $37 \mathrm{U} / \mathrm{ml}$ had prognostic value. Although the optimal cut-off level was not confirmed statistically, $37 \mathrm{U} / \mathrm{ml}$ proved to be a practical and acceptable cut-off point.

In these patients with PDAC, an elevated post-CA 19-9 level was also found to be a serological indicator of positive surgical margins and occult distant metastasis after macroscopically curative resection. Patient age, PV resection, lymph node metastasis, and $\mathrm{R} 1$ resection were higher in patients with elevated levels than in those with normal PostCA 19-9 levels, which is consistent with the findings of previous reports $(9,10,13,14)$. Multivariate analysis showed 
Takagi et al: Predictive Factors for Elevated Postoperative CA 19-9

Table II. Univariate and multivariate logistic regression analysis of factors related to elevated serum Post-CA19-9.

\begin{tabular}{|c|c|c|c|c|c|c|c|}
\hline \multirow[t]{2}{*}{ Variables } & \multirow[t]{2}{*}{ Reference/test } & \multicolumn{3}{|c|}{ Univariate } & \multicolumn{3}{|c|}{ Multivariate } \\
\hline & & $\mathrm{OR}$ & $95 \% \mathrm{CI}$ & $p$-Value & $\mathrm{OR}$ & $95 \% \mathrm{CI}$ & $p$-Value \\
\hline Gender & Female/Male & 0.75 & $0.36-1.57$ & 0.45 & & & \\
\hline Age, y & $<70 / \geq 70$ & 1.05 & $1.01-1.10$ & 0.022 & 1.70 & $0.68-4.22$ & 0.26 \\
\hline Preoperative CA19-9, U/mL & $<400 / \geq 400$ & 6.94 & $3.03-15.9$ & $<0.001$ & 6.48 & $2.53-16.6$ & $<0.001$ \\
\hline Operation method & $\mathrm{DP} / \mathrm{PD}$ or $\mathrm{TP}$ & 1.91 & $0.90-4.00$ & 0.087 & 1.05 & $0.38-2.84$ & 0.92 \\
\hline Resectability status & $\mathrm{R} / \mathrm{BR}$ & 1.56 & $0.73-3.32$ & 0.25 & & & \\
\hline Vascular resection & Not performed/Performed & 2.65 & $1.22-5.73$ & 0.014 & 2.15 & $0.78-5.85$ & 0.14 \\
\hline Historogical grade & $\mathrm{G} 1-\mathrm{G} 2 / \mathrm{G} 3$ & 0.73 & $0.24-2.22$ & 0.58 & & & \\
\hline Tumor stage (UICC 8th ed.) & $\mathrm{T} 1-\mathrm{T} 2 / \mathrm{T} 3-\mathrm{T} 4$ & 1.36 & $0.64-2.85$ & 0.42 & & & \\
\hline Node stage (UICC 8th ed.) & $\mathrm{N} 0 / \mathrm{N} 1-\mathrm{N} 2$ & 3.69 & $1.43-9.54$ & 0.007 & 1.60 & $0.49-5.18$ & 0.43 \\
\hline Intraoperative cytology & negative/positive & 1.48 & $0.38-5.82$ & 0.58 & & & \\
\hline Surgical margin status & $\mathrm{R} 0 / \mathrm{R} 1$ & 15.6 & $1.94-125.0$ & 0.009 & 18.0 & $1.91-170$ & 0.010 \\
\hline Preoperative treatment & Not performed/Performed & 1.57 & $0.54-4.55$ & 0.40 & & & \\
\hline
\end{tabular}

OR: Odds ratio; CI: confidence interval; CA 19-9: carbohydrate antigen 19-9; PV: portal vein; CA: celiac axis; PD: pancreaticoduodenectomy; TP: total pancreatectomy; DP: distal pancreatectomy.

Table III. Types of first site recurrence within postoperative one year associated with Post-CA19-9 value, Pre-CA 19-9 value, and R status.

\begin{tabular}{|c|c|c|c|c|c|c|c|c|c|}
\hline & \multicolumn{3}{|c|}{ Postoperative CA19-9 } & \multicolumn{3}{|c|}{ Preoperative CA19-9 } & \multicolumn{3}{|c|}{ R status } \\
\hline & $\leq 37 \mathrm{U} / \mathrm{ml}$ & $>37 \mathrm{U} / \mathrm{ml}$ & $p$-Value & $\leq 400 \mathrm{U} / \mathrm{ml}$ & $>400 \mathrm{U} / \mathrm{ml}$ & $p$-Value & R 0 & R 1 & $p$-Value \\
\hline Number of patients & 62 & 54 & & 68 & 48 & & 102 & 14 & \\
\hline Any observed metastasis & $20(32)$ & $46(85)$ & $<0.001$ & $27(44)$ & $39(72)$ & $<0.001$ & $54(53)$ & $12(86)$ & 0.023 \\
\hline Hepatic metastasis & $7(11)$ & $29(54)$ & $<0.001$ & $14(23)$ & $22(41)$ & $<0.001$ & $29(28)$ & $7(50)$ & 0.12 \\
\hline Peritoneal dissemination & $0(0)$ & $5(9)$ & 0.020 & $2(3)$ & $3(6)$ & 0.640 & $2(2)$ & $3(21)$ & 0.012 \\
\hline Local recurrence & $3(5)$ & $8(15)$ & 0.11 & $3(5)$ & $8(15)$ & 0.049 & $7(7)$ & $4(29)$ & 0.027 \\
\hline Lymph node metastasis & $5(8)$ & $8(15)$ & 0.38 & $4(6)$ & $9(17)$ & 0.039 & $12(12)$ & $1(7)$ & 1.00 \\
\hline Pulmonary metastasis & $0(0)$ & $1(2)$ & 0.47 & $0(0)$ & $1(2)$ & 0.41 & $1(1)$ & $0(0)$ & 1.00 \\
\hline Other distant metastasis & $1(2)$ & $0(0)$ & 1.00 & $1(2)$ & $0(0)$ & 1.00 & $1(1)$ & $0(0)$ & 1.00 \\
\hline
\end{tabular}

CA 19-9: Carbohydrate antigen 19-9.

that $\mathrm{R} 1$ resection and $\mathrm{CA} 19-9$ level $\geq 400 \mathrm{U} / \mathrm{ml}$ were independent risk factors for elevated Post-CA 19-9 levels. As $\mathrm{R} 1$ resection involves a microscopically detectable residual tumor, the finding that $\mathrm{R} 1$ resection was associated with peritoneal dissemination and local recurrence is not surprising. Previous studies reported that high Pre-CA19-9 levels reflected occult distant metastasis if no distant metastasis was detected by preoperative imaging and intraoperative probing. Others have reported that serum CA 19-9 levels and tumor burden were correlated. Serum CA 19-9 level is routinely used in clinical practice for diagnosis, prognosis, and monitoring treatment response in PDAC $(8,16)$. Pre-CA 19-9 level has been associated with the presence of unresectable disease during staging laparotomy (17) and hepatic micrometastasis detected by intraoperative indocyanin green fluorescent imaging (18). In the present study, a Pre-CA 19-9 level $\geq 400 \mathrm{U} / \mathrm{ml}$ was associated with elevated Post-CA 19-9 level and postoperative recurrence as hepatic metastasis. It is clinically remarkable that elevated Post-CA 19-9 levels reflected Pre-CA 19-9 level $\geq 400 \mathrm{U} / \mathrm{ml}$ as a marker of occult distant metastasis and $\mathrm{R} 1$ resection as evidence of locoregional residual tumor.

To the best of our knowledge, the optimal Pre-CA 19-9 cutoff level for predicting elevated Post-CA 19-9 level has not been previously studied. Previous studies found a significant association or trend toward association of elevated Post-CA 199 and Pre-CA 19-9 levels $(13,14)$. In this patient series, ROC curve analysis and the AUC value indicated that Pre-CA 19-9 had good sensitivity, specificity, and accuracy for predicting elevated Post-CA 19-9 levels. The optimal Pre-CA 19-9 cutoff for predicting elevated Post-CA 19-9 level was found to be $400 \mathrm{U} / \mathrm{ml}$. Other studies have reported Pre-CA 19-9 cut-offs with a prognostic value. Unlike Post-CA 19-9 levels, Pre-CA $19-9$ level $\geq 37 \mathrm{U} / \mathrm{ml}$ had limited prognostic value $(7,10)$. The reported cut-off values with prognostic value ranged from 100-2,000 U/ml (7, 19-21). Thus, the predicted Pre-CA 19-9 
cut-off level of $400 \mathrm{U} / \mathrm{ml}$ is reasonable considering previous reports and is consistent with the finding that elevated Post-CA 19-9 levels were associated with a worse prognosis.

Serum CA 19-9 levels are reportedly useful for perioperative management of patients with $\operatorname{PDAC}(16,22)$, and the results of the present study suggest that patients with elevated Post-CA 19-9 levels are eligible for more intensive adjuvant or organ-specific treatment. Serum CA19-9 level is easy to monitor and has objective value, and prediction of elevated Post-CA19-9 levels can be helpful in selecting previously advocated preoperative treatments $(23,24)$. In this patient series, high Pre-CA 19-9 levels supported preoperative treatment because of the increased risk of hepatic metastasis. As previously reported Pre- and Post-CA 19-9 cut-off levels vary $(7,19-21)$, further studies are required to confirm the optimal cut-offs.

The study has certain limitations. These include the small sample size and single-center retrospective study design. As several biases may have affected the results, the findings should be further validated in a different patient series. In addition, occult distant metastasis was not directly evaluated. The evidence that Post-CA 19-9 levels indicated occult distant metastasis was obtained from statistical analysis and was supported by previous reports. The use of diagnostic tools to detect occult distant metastasis might provide definitive evidence of this relationship. Although, intraoperative indocyanin green fluorescent imaging is effective for probing occult hepatic metastasis, it is not effective for finding deep hepatic lesions (18). Development of effective methods for preoperative detection of occult distant metastasis is thus warranted. Moreover, therapeutic strategies using CA 19-9 levels cannot be applicable to all patients with PDAC because some patients with Lewis Antigen negative do not secrete CA 19-9. In addition, the presence of obstructive jaundice can affect CA 19-9 level. Considering these cases, CA19-9 as well as other biomarkers can be useful to improve the treatment strategy for patients with PDAC $(25,26)$.

In conclusion, elevated Post-CA 19-9 level was associated with a poor prognosis and predicted by positive surgical margin and Pre-CA19-9 level $\geq 400 \mathrm{U} / \mathrm{ml}$ in patients with PDAC who received macroscopically curative resection. Elevated Post-CA 19-9 level was shown to imply a locoregional residual tumor and occult distant metastasis. Although the study results need to be verified by largesample, multicentric, and prospective studies, predicted or existing elevated Post-CA 19-9 levels could be an adequate indication for the development of novel and alternative treatment strategies for the treatment of patients with PDAC.

\section{Conflicts of Interest}

The Authors declare no conflicts of interests for the present article.

\section{Authors' Contributions}

C.T. designed the study, collected and analyzed the data, and wrote the manuscript. Y.K., H.S., S.H., M.T., I.O., S.H., and Y.O. interpreted the data and reviewed the manuscript.

\section{Acknowledgements}

The Authors would like to thank Enago (www.enago.jp) for the English language review.

\section{References}

1 Allen PJ, Kuk D, Castillo CF, Basturk O, Wolfgang CL, Cameron JL, Lillemoe KD, Ferrone CR, Morales-Oyarvide V, He J, Weiss MJ, Hruban RH, Gönen M, Klimstra DS and Mino-Kenudson M: Multiinstitutional Validation Study of the American Joint Commission on Cancer (8th Edition) Changes for T and N Staging in Patients With Pancreatic Adenocarcinoma. Ann Surg 265: 185-191, 2017. PMID: 27163957. DOI: $10.1097 /$ SLA.0000000000001763

2 de Geus SWL, Eskander MF, Bliss LA, Kasumova GG, Ng SC, Callery MP and Tseng JF: Neoadjuvant therapy versus upfront surgery for resected pancreatic adenocarcinoma: A nationwide propensity score matched analysis. Surgery 161: 592-601, 2017. PMID: 28341441. DOI: 10.1016/j.surg.2016.08.040

3 Uesaka K, Boku N, Fukutomi A, Okamura Y, Konishi M, Matsumoto I, Kaneoka Y, Shimizu Y, Nakamori S, Sakamoto H, Morinaga S, Kainuma O, Imai K, Sata N, Hishinuma S, Ojima $\mathrm{H}$, Yamaguchi R, Hirano S, Sudo T, Ohashi Y and JASPAC 01 Study Group: Adjuvant chemotherapy of S-1 versus gemcitabine for resected pancreatic cancer: a phase 3, open-label, randomised, non-inferiority trial (JASPAC 01). Lancet (London, England) 388: 248-257, 2016. PMID: 27265347. DOI: 10.1016/S0140-6736(16)30583-9

4 Neoptolemos JP, Palmer DH, Ghaneh P, Psarelli EE, Valle JW, Halloran CM, Faluyi O, O'Reilly DA, Cunningham D, Wadsley J, Darby S, Meyer T, Gillmore R, Anthoney A, Lind P, Glimelius B, Falk S, Izbicki JR, Middleton GW, Cummins S, Ross PJ, Wasan H, McDonald A, Crosby T, Ma YT, Patel K, Sherriff D, Soomal R, Borg D, Sothi S, Hammel P, Hackert T, Jackson R, Büchler MW and European Study Group for Pancreatic Cancer: Comparison of adjuvant gemcitabine and capecitabine with gemcitabine monotherapy in patients with resected pancreatic cancer (ESPAC-4): a multicentre, open-label, randomised, phase 3 trial. Lancet (London, England) 389: 1011-1024, 2017. PMID: 28129987. DOI: 10.1016/S0140-6736(16)32409-6

5 Sho M, Akahori T, Tanaka T, Kinoshita S, Tamamoto T, Nomi T, Yamato I, Hokuto D, Yasuda S, Kawaguchi C, Nishiofuku H, Marugami N, Enomonoto Y, Kasai T, Hasegawa M, Kichikawa K and Nakajima Y: Pathological and clinical impact of neoadjuvant chemoradiotherapy using full-dose gemcitabine and concurrent radiation for resectable pancreatic cancer. J Hepatobiliary Pancreat Sci 20: 197-205, 2013. PMID: 22766692. DOI: 10.1007/s00534012-0532-8

6 Oettle H, Neuhaus P, Hochhaus A, Hartmann JT, Gellert K, Ridwelski K, Niedergethmann M, Zülke C, Fahlke J, Arning MB, Sinn M, Hinke A and Riess H: Adjuvant chemotherapy with gemcitabine and long-term outcomes among patients with resected pancreatic cancer: the CONKO-001 randomized trial. 
JAMA 310: 1473-81, 2013. PMID: 24104372. DOI: 10.1001/ jama.2013.279201

7 Ferrone CR, Finkelstein DM, Thayer SP, Muzikansky A, Fernandez-delCastillo C and Warshaw AL: Perioperative CA199 levels can predict stage and survival in patients with resectable pancreatic adenocarcinoma. J Clin Oncol 24: 2897-2902, 2006. PMID: 16782929 . DOI: 10.1200/JCO.2005.05.3934

8 Schlieman MG, Ho HS and Bold RJ: Utility of tumor markers in determining resectability of pancreatic cancer. Arch Surg 138: 951-955; discussion 955-956, 2003. PMID: 12963650. DOI: 10.1001/archsurg.138.9.951

9 Berger AC, Garcia M, Hoffman JP, Regine WF, Abrams RA, Safran H, Konski A, Benson AB, MacDonald J and Willett CG: Postresection CA 19-9 predicts overall survival in patients with pancreatic cancer treated with adjuvant chemoradiation: A prospective validation by RTOG 9704. J Clin Oncol 26: 59185922, 2008. PMID: 19029412. DOI: 10.1200/JCO.2008.18.6288

10 Hata S, Sakamoto Y, Yamamoto Y, Nara S, Esaki M, Shimada K and Kosuge T: Prognostic impact of postoperative serum CA 199 levels in patients with resectable pancreatic cancer. Ann Surg Oncol 19: 636-641, 2012. PMID: 21863360. DOI: 10.1245/ s10434-011-2020-9

11 Kondo N, Murakami Y, Uemura K, Nakagawa N, Takahashi S, Ohge $\mathrm{H}$ and Sueda T: Pancreatology Comparison of the prognostic impact of pre- and post-operative CA19-9, SPan-1, and DUPAN-II levels in patients with pancreatic carcinoma. Pancreatology 17: 95-102, 2018. PMID: 20336387. DOI: 10.1245/s10434-010-1033-0

12 James D. Brierley, Mary K. Gospodarowicz CW: TNM Classification of Malignant Tumours, 8th Edition. WileyBlackwell, 2017.

13 Motoi F, Rikiyama T, Katayose Y, Egawa SI and Unno M: Retrospective evaluation of the influence of postoperative tumor marker status on survival and patterns of recurrence after surgery for pancreatic cancer based on RECIST guidelines. Ann Surg Oncol 18: 371-379, 2011. PMID: 20842460. DOI: 10.1245/ s10434-010-1311-x

14 Abdel-Misih SRZ, Hatzaras I, Schmidt C, Saab TB, Klemanski D, Muscarella P, Melvin WS, Ellison EC and Bloomston M: Failure of normalization of CA19-9 following resection for pancreatic cancer is tantamount to metastatic disease. Ann Surg Oncol 18: 1116-1121, 2011. PMID: 21042945. DOI: 10.1245/ s10434-010-1397-1

15 Kinsella TJ, Seo Y, Willis J, Stellato TA, Siegel CT, Harpp D, Willson JK, Gibbons J, Sanabria JR, Hardacre JM and Schulak JP: The impact of resection margin status and postoperative CA19-9 levels on survival and patterns of recurrence after postoperative high-dose radiotherapy with 5-FU - Based concurrent chemotherapy for resectable pancreatic cancer. Am J Clin Oncol Cancer Clin Trials 31: 446-453, 2008. PMID: 18838880. DOI: $10.1097 / C O C .0 b 013 \mathrm{e} 318168 \mathrm{f} 6 \mathrm{c} 4$

16 Hartwig W, Strobel O, Hinz U, Fritz S, Hackert T, Roth C, Büchler MW and Werner J: CA19-9 in potentially resectable pancreatic cancer: Perspective to adjust surgical and perioperative therapy. Ann Surg Oncol 20: 2188-2196, 2013. PMID: 23247983. DOI: 10.1245/s10434-012-2809-1

17 Karachristos A, Scarmeas N and Hoffman JP: CA 19-9 levels predict results of staging laparoscopy in pancreatic cancer. J Gastrointest Surg 9: 1286-1292, 2005. PMID: 16332484. DOI: 10.1016/j.gassur.2005.06.008
18 Yokoyama N, Otani T, Hashidate H, Maeda C, Katada T, Sudo N, Manabe S, Ikeno Y, Toyoda A and Katayanagi N: Real-time detection of hepatic micrometastases from pancreatic cancer by intraoperative fluorescence imaging: Preliminary results of a prospective study. Cancer 118: 2813-2819, 2012. PMID: 21990070. DOI: $10.1002 / \mathrm{cncr} .26594$

19 Liu L, Xu H, Wang W, Wu C, Chen Y, Yang J, Cen P, Xu J, Liu C, Long J, Guha S, Fu D, Ni Q, Jatoi A, Chari S, McCleary-Wheeler AL, Fernandez-Zapico ME, Li M and Yu X: A preoperative serum signature of $\mathrm{CEA}^{+} / \mathrm{CA} 125^{+/ C A} 19-9 \geq 1000 \mathrm{U} / \mathrm{mL}$ indicates poor outcome to pancreatectomy for pancreatic cancer. Int J Cancer 136: 2216-2227, 2015. PMID: 25273947. DOI: 10.1002/ijc.29242

20 Sugiura T, Uesaka K, Kanemoto H, Mizuno T, Sasaki K, Furukawa H, Matsunaga K and Maeda A: Serum CA19-9 is a significant predictor among preoperative parameters for early recurrence after resection of pancreatic adenocarcinoma. J Gastrointest Surg 16: 977-985, 2012. PMID: 22411488. DOI: 10.1007/s11605-012-1859-9

21 Dong Q, Yang X, Zhang Y, Jing W, Zheng L, Liu Y and Qu X: Elevated serum CA19-9 level is a promising predictor for poor prognosis in patients with resectable pancreatic ductal adenocarcinoma: a pilot study. World J Surg Oncol 12: 171, 2014. PMID: 24890327. DOI: 10.1186/1477-7819-12-171

22 Humphris JL, Chang DK, Johns AL, Scarlett CJ, Pajic M, Jones MD, Colvin EK, Nagrial A, Chin VT, Chantrill LA, Samra JS, Gill AJ, Kench JG, Merrett ND, Das A, Musgrove EA, Sutherland RL and Biankin AV: The prognostic and predictive value of serum CA19.9 in pancreatic cancer. Ann Oncol 23: 1713-1722, 2012. PMID: 22241899. DOI: 10.1093/annonc/ mdr561

23 Kamachi H, Tsuruga Y, Orimo T, Wakayama K, Shimada S, Nagatsu A, Yokoo H, Kamiyama T, Katoh N and Taketomi A: R0 resection for locally advanced pancreatic cancer with lowdose gemcitabine with wide irradiation area as neoadjuvant chemoradiotherapy. In Vivo 32: 1183-1191. PMID: 30150442. DOI: 10.21873 /invivo. 11362

24 Katz MHG, Shi Q, Ahmad SA, Herman JM, Marsh R de W, Collisson E, Schwartz L, Frankel W, Martin R, Conway W, Truty M, Kindler H, Lowy AM, Bekaii-Saab T, Philip P, Talamonti M, Cardin D, LoConte N, Shen P, Hoffman JP and Venook AP: Preoperative modified FOLFIRINOX treatment followed by capecitabine-based chemoradiation for borderline resectable pancreatic cancer: Alliance for clinical trials in oncology trial A021101. JAMA Surg 151: e161137, 2016. PMID: 27275632. DOI: 10.1001/jamasurg.2016.1137

25 Karasek P, Gablo N, Hlavsa J, Kiss I, Vychytilova-Faltejskova P, Hermanova M, Kala Z, Slaby O and Prochazka V: Pre-operative plasma miR-21-5p is a sensitive biomarker and independent prognostic factor in patients with pancreatic ductal adenocarcinoma undergoing surgical resection. Cancer Genomics Proteomics 15: 321-327. PMID: 29976637. DOI: 10.21873/cgp.20090

26 Li H, Mao Y, Xiong Y, Zhao HH, Shen F, Gao X, Yang P, Liu X and $\mathrm{Fu} \mathrm{D}$ : A Comprehensive proteome analysis of peripheral blood mononuclear cells (PBMCs) to identify candidate biomarkers of pancreatic cancer. Cancer Genomics Proteomics 16: 81-89. PMID: 30587502. DOI: 10.21873/cgp.20114

Received April 23, 2019

Revised May 23, 2019

Accepted May 24, 2019 